\title{
ANALISIS DAN PREDIKSI PENYAKIT JANTUNG KORONER DI KOTA AMBON MENGGUNAKAN JARINGAN SARAF TIRUAN
}

\author{
Dorteus Lodewyik Rahakbauw ${ }^{1}$, Ferry Kondo Lembang ${ }^{2}$, \\ Yuniasih M. J. Taihuttu ${ }^{3}$ \\ 1,2 Staf Dosen Jurusan Matematika FMIPA UNPATTI \\ ${ }^{3}$ Staf Dosen Pendidikan Dokter Fakultas Kedokteran UNPATTI \\ Jl. Ir. M. Putuhena, Kampus Unpatti, Poka-Ambon \\ (Telp: 085776707053 e-mail: lodewyik@gmail.com)
}

\begin{abstract}
Abstrak
Penyakit jantung koroner disebabkan oleh pembentukan plak yang terdiri atas kolesterol, kalsium dan bahan lain di dalam pembuluh darah yang lama-kelamaan menumpuk di dalam dinding pembuluh darah jantung (arteri koronaria) serta arteri di tempat lain. Di Indonesia 36 juta penduduk menderita penyakit ini dan $80 \%$ diantaranya meninggal akibat serangan jantung mendadak, selain itu indonesia menduduki urutan 5 dunia untuk PJK. Penyakit Jantung Koroner (PJK) merupakan keadaan dimana terjadi penimbunan plak pembuluh darah koroner. Diperlukan diagnosa yang tepat dari pihak medis untuk pemberian pengobatan yang tepat bagi penderita PJK.

Dalam penelitian ini akan diprediksi PJK ini menggunakan metode pengenalan pola dari data catatan rekam medis penderita penyakit jantung koroner yang ada di kota Ambon periode 2014-2015 menggunakan metode Jaringan Syaraf Tiruan (JST) Backpropagation . Berdasarkan data rekam medis penderita penyakit jantung koroner dan orang sehat tersebut dilakukan pelatihan terhadap JST ini, yang nantinya JST ini mampu mengenali polanya. Terdapat 13 faktor risiko yang merupakan node input jaringan dan juga merupakan penyebab timbulnya penyakit jantung koroner, node input tersebut adalah: jenis kelamin, merokok, kelebihan berat badan, pengguna alkohol, pola makan garam yang tinggi, pola makan lemak yang tinggi, olahraga, keturunan, tekanan darah, kolesterol, tekanan gula, tekanan jantung, dan kebiasaan sehari-hari. Dalam penelitian ini data akan langsung diuji dengan 5 pola jaringan: 13-2-1, 13-3-1, 13-4-1, 13-5-1, dan 13-6-1 dimana 13 node input sebagai masukkan, unit hidden layer ditentukan secara acak dengan rentang 2 sampai 6 dan 1 unit output dengan fungsi aktivasi sigmoid. Pengujian jaringan saraf tiruan ini dilakukan secara berulang sampai menghasilkan error keluaran yang terkecil pada setiap output data jaringan bersamaan dengan mengubah setiap fungsi aktivasi yang ada pada setiap lapisan pola jaringan saraf tiruan yang dipakai. Setelah proses pelatihan dilakukan, diperoleh konfigurasi jaringan yang terbaik dari 5 tipe yang diuji yaitu tipe dengan 13 input dan 6 hidden layer dengan 1 output (13-6-1) dengan bobot terbaik yang sudah diperoleh dengan kemampuan jaringan mendeteksi seseorang terkena penyakit jantung koroner dengan skala error 0,0009 sampai 0,0727 yang dipandang sangat kecil error yang diperoleh dengan persamaan regresi yang terbentuk adalah $\mathrm{y}=0,91 \mathrm{~T}+0,079$ dengan koefisien korelasi sebesar 0,91205 .
\end{abstract}

Kata Kunci: Jaringan Saraf Tiruan, Backpropagation, Penyakit Jantung Koroner.

\section{ANALYSIS AND PREDICTION OF CORONARY HEART DISEASE IN AMBON CITY USING NEURAL NETWORK}

\begin{abstract}
Coronary heart disease is caused by the formation of plaque consisting of cholesterol, calcium and other substances in the blood vessels that gradually accumulate inside the walls of the coronary arteries (coronary arteries) and arteries elsewhere. In Indonesia 36 million people suffer from this disease and $80 \%$ of them died from sudden cardiac arrest, in addition Indonesia is ranked 5th world for CHD. Coronary Heart Disease (CHD) is a condition where there is accumulation of coronary artery plaque. Medical diagnosis is necessary for proper treatment of CHD patients.

In this research will be predicted PJK uses pattern recognition method of medical record records data of patients with coronary heart disease in Ambon city period 2014-2015 using Backpropagation Neural Network (ANN) method. Based on medical record data of patients with coronary heart disease and
\end{abstract}


healthy people are training on this ANN, which later ANN is able to recognize the pattern. There are 13 risk factors that are the network input nodes and are also the cause of coronary heart disease, the input nodes are: sex, smoking, overweight, alcohol users, high salt diet, high fat diet, exercise, offspring, blood pressure, cholesterol, sugar pressure, heart pressure, and daily habits. In this research the data will be directly tested with 5 network patterns: 13-2-1, 13-3-1, 13-4-1, 13-5-1, and 13-6-1 where 13 input nodes as input, The hidden layer is randomly assigned to the range 2 to 6 and 1 unit of output with the sigmoid activation function. Testing of artificial neural networks is done repeatedly to produce the smallest output error on each network data output simultaneously by changing every activation function that exists on every layer of artificial neural network patterns used. After the training process is done, the best network configuration of the 5 types tested is the type with 13 inputs and 6 hidden layers with 1 output (13-6-1) with the best weights that have been obtained with the ability of the network to detect a person affected by coronary heart disease with Scale error 0.0009 to 0,0727 which is considered very small error obtained with regression equation formed is $\mathrm{y}=0,91 \mathrm{~T}+0,079$ with correlation coefficient equal to 0,91205 .

Keywords: Artificial Neural Network, Backpropagation, Coronary Heart Disease.

\section{Pendahuluan}

Setiap tahunnya lebih dari 36 juta orang meninggal karena Penyakit Tidak Menular (PTM) (63\% dari seluruh kematian). Lebih dari 9 juta kematian yang disebabkan oleh penyakit tidak menular terjadi sebelum usia 60 tahun, dan 90\% dari kematian "dini” tersebut terjadi di negara berpenghasilan rendah dan menengah. Secara global PTM penyebab kematian nomor satu setiap tahunnya adalah penyakit kardiovaskuler. Penyakit kardiovaskuler adalah penyakit yang disebabkan gangguan fungsi jantung dan pembuluh darah, seperti: Penyakit Jantung Koroner, Penyakit Gagal jantung atau Payah Jantung, Hipertensi dan Stroke (Kementerian Kesehatan RI, 2014). Hiperkolesterolemia adalah peninggian kadar kolesterol didalam darah. Tingginya kadar kolesterol darah merupakan problem yang serius karena merupakan salah satu factor resiko utama terjadinya penyakit jantung koroner. Penyakit jantung koroner (PJK) mempunyai angka kematian dan kesakitan yang tinggi. Walaupun penyebab dasar terjadinya penyakit jantung koroner belum diketahui dengan pasti, para ahli telah mengidentifikasi sejumlah faktor yang berhubungan dengan terjadinya penyakit jantung yang disebut sebagai faktor risiko. Faktor risiko penyakit jantung koroner ada yang membaginya dalam faktor risiko primer (independen) dan sekunder [1], yaitu:

1) Faktor risiko primer; faktor ini dapat menyebabkan gangguan arteri berupa aterosklerosis tanpa harus dibantu oleh factor lain (independen), termasuk faktor risiko primer, yaitu hiperlidemi, merokok, dan hipertensi.

2) Faktor risiko sekunder; Faktor ini baru dapat menimbulkan kelainan arteri bila ditemukan faktor lain secara bersamaan, termasuk faktor risiko sekunder, yaitu diabetes melitus (DM), obesitas, stres, kurang olah raga, alkohol, dan riwayat keluarga.

Mengingat faktor-faktor yang menyebabkan PJK sangat kompleks maka peluang seseorang untuk terkena PJK juga sangat tinggi, sehingga diperlukan suatu solusi untuk menyelesaikan masalah tersebut dalam bentuk pemodelan. Dalam bentuk pemodelan tersebut dapat ditentukan seseorang tergolong penderita PJKsehingga dapat lebih diwaspadai lebih dini. Dari berbagai macam kemungkinan penyebab PJK yang telah disebutkan diatas, faktor umum yang mempengaruhi adalah makanan. Dalam hal ini jaringan Syaraf Tiruan merupakan salah satu bentuk khusus pemrograman komputasi yang dapat digunakan untuk membuat pemodelan penyakit jantung koroner. Algoritma JST yang tepat diterapkan dalam masalah ini adalah backpropagation karena dapat mempredikisi seseorang tergolong penderita berdasarkan data rekam medis yang lain. Dengan mengambil $80 \%$ data sebagai pelatihan dan $20 \%$ data sebagai data pengujian untuk pengenalan pola penyakit jantung koroner.

\section{Tinjauan Pustaka}

\subsection{Artificial Intelligence}

Artificial intelligence atau kecerdasan buatan merupakan sebuah studi tentang bagaimana membuat komputer melakukan hal-hal yang pada saat ini dapat dilakukan lebih baik oleh manusia. Dalam wikipedia,2017 Kecerdasan Buatan atau kecerdasan yang ditambahkan kepada suatu sistem yang bisa diatur dalam konteks ilmiah atau Intelegensi Artifisial didefinisikan sebagai kecerdasan entitas ilmiah. Sistem 
seperti ini umumnya dianggap komputer. Kecerdasan diciptakan dan dimasukkan ke dalam suatu mesin (komputer) agar dapat melakukan pekerjaan seperti yang dapat dilakukan manusia. Beberapa macam bidang yang menggunakan kecerdasan buatan antara lain sistem pakar, permainan komputer (games), logika fuzzy, jaringan syaraf tiruan dan robotika. Pada awal abad 17, René Descartes mengemukakan bahwa tubuh hewan bukanlah apa-apa melainkan hanya mesin-mesin yang rumit. Blaise Pascal menciptakan mesin penghitung digital mekanis pertama pada 1642. Pada 19, Charles Babbage dan Ada Lovelace bekerja pada mesin penghitung mekanis yang dapat diprogram.

Bertrand Russell dan Alfred North Whitehead menerbitkan Principia Mathematica, yang merombak logika formal. Warren McCulloch dan Walter Pitts menerbitkan "Kalkulus Logis Gagasan yang tetap ada dalam Aktivitas " pada 1943 yang meletakkan pondasi untuk jaringan syaraf. Tahun 1950-an adalah periode usaha aktif dalam AI. Program AI pertama yang bekerja ditulis pada 1951 untuk menjalankan mesin Ferranti Mark I di University of Manchester (UK): sebuah program permainan naskah yang ditulis oleh Christopher Strachey dan program permainan catur yang ditulis oleh Dietrich Prinz. John McCarthy membuat istilah "kecerdasan buatan " pada konferensi pertama yang disediakan untuk pokok persoalan ini, pada 1956. Dia juga menemukan bahasa pemrograman Lisp. Alan Turing memperkenalkan "Turing test" sebagai sebuah cara untuk mengoperasionalkan test perilaku cerdas.

Selama tahun 1960-an dan 1970-an, Joel Moses mendemonstrasikan kekuatan pertimbangan simbolis untuk mengintegrasikan masalah di dalam program Macsyma, program berbasis pengetahuan yang sukses pertama kali dalam bidang matematika. Marvin Minsky dan Seymour Papert menerbitkan Perceptrons, yang mendemostrasikan batas jaringan syaraf sederhana dan Alain Colmerauer mengembangkan bahasa komputer Prolog. Ted Shortliffe mendemonstrasikan kekuatan sistem berbasis aturan untuk representasi pengetahuan dan inferensi dalam diagnosa dan terapi medis yang kadangkala disebut sebagai sistem pakar pertama. Hans Moravec mengembangkan kendaraan terkendali komputer pertama untuk mengatasi jalan berintang yang kusut secara mandiri. Pada tahun 1980-an, jaringan syaraf digunakan secara meluas dengan algoritma perambatan balik, pertama kali diterangkan oleh Paul John Werbos pada 1974. Pada tahun 1982, para ahli fisika seperti Hopfield menggunakan teknik-teknik statistika untuk menganalisis sifat-sifat penyimpanan dan optimasi pada jaringan syaraf. Para ahli psikologi, David Rumelhart dan Geoff Hinton, melanjutkan penelitian mengenai model jaringan syaraf pada memori. Pada tahun 1985-an sedikitnya empat kelompok riset menemukan kembali algoritma pembelajaran propagansi balik (Back-Propagation learning). Algoritma ini berhasil diimplementasikan ke dalam ilmu komputer dan psikologi. Tahun 1990-an ditandai perolehan besar dalam berbagai bidang AI dan demonstrasi berbagai macam aplikasi.

\subsection{Jaringan Syaraf Tiruan}

Jaringan syaraf tiruan merupakan salah satu kecerdasan buatan, yang merupakan representasi tiruan dari otak manusia yang selalu mencoba mensimulasikan proses pembelajaran pada otak manusia tersebut. Model ini merupakan model kotak hitam (blackboxmodel), sehingga dalam penerapannya tidak membutuhkan pengetahuan yang kompleks antar berbagai aspek dalam melakukan proses pemodelan faktorfaktor tersebut.

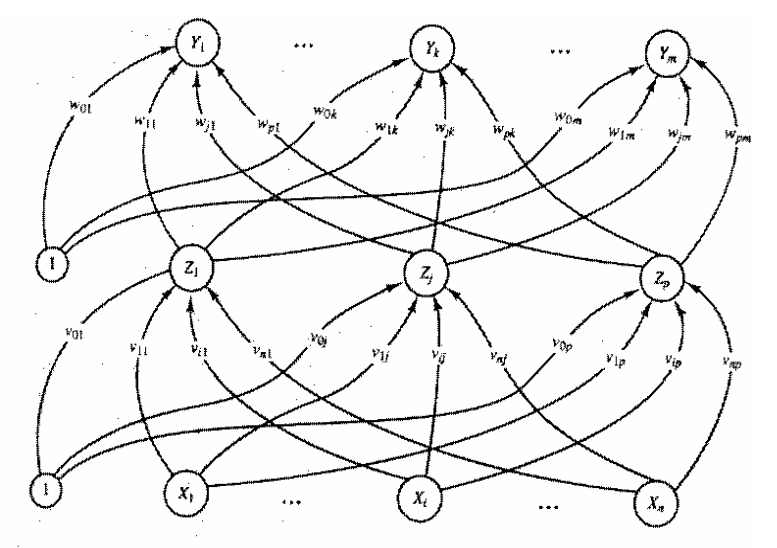

Gambar 1. Jaringan Syaraf Tiruan Backpropagation dengan satu hiddenlayer 
Effendi, dkk pada tahun 2008 memprediksi PJK dengan faktor resiko dengan variabel input yang berjumlah 9 unit sel dan data yang dilatih 40 data rekam medis pasien dan diperoleh Jaringan Syaraf dapat mengenali $80 \%$ data baru sesuai dengan target dan $20 \%$ data baru tidak sesuai dengan target [1]. Lestari pada tahun 2014 melakukan penelitian dengan menggunakan algoritma klasifikasi nearest neighbor (k-nn) untuk mendeteksi penyakit jantung dengan nilai akurasi $70 \%$ selain itu dia juga menyatakan bahwa komparasi terhadap algoritma atau metode data mining lainnya dalam mendeteksi penyakit jantung, perlu dilakukan untuk mengetahui algoritma mana yang lebih akurat dan efisien, sehingga dapat ditentukan algoritma yang tepat untuk mendeteksi penyakit jantung [6].

\subsection{Propagasi Balik (Backpropagation)}

Backpopagation merupakan algoritma pembelajaran yang terawasi dan biasanya dan biasanya digunakan untuk perceptron banyak lapisan untuk mengubah bobot-bobot yang terhubung dengan neuronneuron yang ada pada lapisan tersembunyinya. Algoritma inimenggunakan error output untuk mengubah nilai bobot-bobotnya dalam arah mundur (backward). Untuk mendapatkan error ini, tahap perambatan maju (forward propagation) harus dikerjakan terlebih dahulu. Perambatan maju, neuron-neuron diaktifkan dengan menggunakan fungsi aktivasi yang dapat dideferensiasikan, seperti:

$$
\begin{aligned}
& \text { a. Sigmoid, } y=f(x)=\frac{1}{1+e^{-\sigma x}} \\
& \text { b. Tansig, } y=f(x)=\frac{e^{x}-e^{-x}}{e^{x}+e^{-x}} \\
& \text { c. Purelin, } y=f(x)=x
\end{aligned}
$$

dapat digambarkan arsitekturnya pada gambar 1.

Adapun algoritma trainingbackpropagation adalah sebagai berikut :

Step 0 : Inisialisasi nilai bobot dengan nilai acak yang kecil.

Step 1 : Selama kondisi berhenti masih belum terpenuhi, kerjakan step 2 - 9.

Step 2 :Untuk tiap pasangan pelatihan (s:t), kerjakan step 3 - 8.

\section{Feedforward :}

Step 3 : Setiap unit input $\left(X_{i}, i=1, \ldots, n\right)$ menerima sinyal inputx $x_{i}$ dan menyebarkan sinyal itu ke seluruh unit pada layer berikutnya (hidden layer)

Step 4 : Setiap unit dalam $\left(Z_{j}, j=1, \ldots, p\right)$ hitung nilai input dengan menggunakan nilai bobotnya

$$
z_{-} i n_{j}=v_{0 j}+\sum_{i=1}^{n} x_{i} v_{i j}
$$

Selanjutnya hitung nilai output dengan menggunakan fungsi aktivasi yang dipilih

$$
z_{j}=f\left(z_{-} i n_{j}\right)
$$

Hasil fungsi tersebut dikirim ke semua unit pada layer berikutnya (unit output).

Step 5 : Untuk tiap unit output $\left(Y_{k}, k=1, . ., m\right)$ hitung nilai input dengan menggunakan nilai bobot-nya

$$
y_{-} i n_{k}=w_{0 k}+\sum_{j=1}^{p} z_{j} w_{j k}
$$

Kemudian hitung nilai output dengan menggunakan fungsi aktivasi

$$
y_{k}=f\left(y_{-} i n_{k}\right)
$$

\section{Backpropagation Of Error}

Step 6 : Setiap unit output $\left(Y_{k}, k=1, . ., m\right)$ menerima pola target yang bersesuaian dengan pola input dan kemudian hitung error informasi 


$$
\delta_{k}=\left(t_{k}-y_{k}\right) f^{\prime}\left(y_{-} i n_{k}\right)
$$

Kemudian hitung koreksi nilai bobot yang akan digunakan untuk memperbaharui nilai bobot $w_{j k}$ :

$$
\Delta w_{j k}=\alpha \delta_{k} z_{j}
$$

Hitung koreksi nilai bias yang akan digunakan untuk memperbaharui nilai $w_{o k}$ :

$$
\Delta w_{0 k}=\alpha \delta_{k}
$$

dan nilai $\delta_{k}$ dikirim ke unit pada layer sebelumnya.

Step 7 : Setiap unit dalam $\left(Z_{j}, j=1, \ldots, p\right)$ hitung delta input yang berasal dari unit pada layer di atasnya :

$$
\delta_{-} i n_{j}=\sum_{k=1}^{m} \delta_{k} w_{j k}
$$

Kemudian nilai tersebut dikalikan dengan nilai turunan dari fungsi aktivasi

untuk menghitung error informasi :

$$
\delta_{j}=\delta_{-} i n_{j} f^{\prime}\left(z_{-} i n_{j}\right)
$$

Hitung koreksi nilai bobot yang kemudian digunakan untuk memperbaharui nilai $v_{i j}$

$$
\Delta v_{i j}=\alpha \delta_{j} x_{i}
$$

dan hitung nilai koreksi bias yang kemudian digunakan untuk memperbaharui $v_{o j}$

$$
\Delta v_{o j}=\alpha \delta_{j}
$$

\section{Update nilai bobot dan bias :}

Step 8: Setiap unit output $\left(Y_{k}, k=1, \ldots, m\right)$ update bias dan bobotnya $(\mathrm{j}=0, \ldots, p)$

$$
w_{j k}(\text { new })=w_{j k}(\text { old })+\Delta w_{j k}
$$

Setiap unit hidden $\left(Z_{j}, j=1, \ldots, p\right)$ update bias dan bobotnya $(\mathrm{i}=0, \ldots, n)$

$$
v_{i j}(\text { new })=v_{i j}(\text { old })+\Delta v_{i j}
$$

Step 9 : Uji: apakah kondisi berhenti sudah terpenuhi? [2]

\section{Hasil dan Pembahasan}

\subsection{Data Input}

Populasi dari penelitian ini adalah pasien yang sedang menjalani perawatan di RSUD Dr. M. Haulussy Ambon sepanjang bulan Juni 2015 yang berjumlah 20 orang, dimana responden merupakan penderita (case) Jantung koroner. Data untuk kelompok case merupakan data primer maupun sekunder, diperoleh menggunakan media komunikasi berupa kuesioner dan data rekam medik pasien yang terdiagnosis menderita Jantung koroner yang berumur 15 tahun keatas dan sedang menjalani perawatan di IRA (Instalasi Rawat Inap) pada saat survei dilakukan. variabel data yang diperoleh bersesuaian dengan tabel berikut 
Tabel 1. Daftar kriteria dalam deteksi penyakit jantung

\begin{tabular}{|c|c|c|}
\hline Kriteria & Keterangan & Bobot \\
\hline $\begin{array}{l}\text { Jenis Kelamin } \\
\text { (Laki-Laki; } \\
\text { Perempuan) }\end{array}$ & $\begin{array}{l}\text { Umur }<30 \\
\text { Umur }>30<50 \\
\text { Umur }>50<70 \\
\text { Umur }>70\end{array}$ & $\begin{array}{l}0.1 \\
0.3 \\
0.7 \\
0.8\end{array}$ \\
\hline Merokok & $\begin{array}{l}\text { Tidak } \\
\text { Masa Lalu } \\
\text { Ya }\end{array}$ & $\begin{array}{l}0.1 \\
0.3 \\
0.6\end{array}$ \\
\hline $\begin{array}{l}\text { Kelebihan berat } \\
\text { badan }\end{array}$ & $\begin{array}{l}\text { Ya } \\
\text { Tidak }\end{array}$ & $\begin{array}{l}0.8 \\
0.1\end{array}$ \\
\hline Pengguna alkohol & $\begin{array}{l}\text { Tidak } \\
\text { Masa Lalu } \\
\text { Ya }\end{array}$ & $\begin{array}{l}0.1 \\
0.3 \\
0.6\end{array}$ \\
\hline $\begin{array}{l}\text { Pola makan garam } \\
\text { yang tinggi }\end{array}$ & $\begin{array}{l}\text { Ya } \\
\text { Tidak }\end{array}$ & $\begin{array}{l}0.9 \\
0.1\end{array}$ \\
\hline $\begin{array}{l}\text { Pola makan lemak } \\
\text { yang tinggi }\end{array}$ & $\begin{array}{l}\text { Ya } \\
\text { Tidak }\end{array}$ & $\begin{array}{l}0.9 \\
0.1\end{array}$ \\
\hline Olah raga & $\begin{array}{l}\text { Ya } \\
\text { Tidak }\end{array}$ & $\begin{array}{l}0.1 \\
0.6\end{array}$ \\
\hline Keturunan & $\begin{array}{l}\text { Ya } \\
\text { Tidak }\end{array}$ & $\begin{array}{l}0.7 \\
0.1\end{array}$ \\
\hline Tekanan Darah & $\begin{array}{l}\text { Normal }(130 / 89) \\
\text { Rendah }(<119 / 79) \\
\text { Tinggi }(>200 / 160 \\
\end{array}$ & $\begin{array}{l}0.1 \\
0.8 \\
0.9\end{array}$ \\
\hline Kholestrol & $\begin{array}{l}\text { Sangat Tinggi }>200 \\
\text { Tinggi } 160-200 \\
\text { Normal }<160\end{array}$ & $\begin{array}{l}0.9 \\
0.8 \\
0.1\end{array}$ \\
\hline Tekanan Gula & $\begin{array}{l}\text { Tinggi }>120 \text { dan }<400 \\
\text { Normal } 90-120 \\
\text { Rendah }<90\end{array}$ & $\begin{array}{l}0.5 \\
0.1 \\
0.4\end{array}$ \\
\hline Tekanan Jantung & $\begin{array}{l}\text { Rendah }<60 \mathrm{bpm} \\
\text { Normal } 60 \mathrm{bpm}-100 \mathrm{bpm} \\
\text { Tinggi }>100 \mathrm{bpm}\end{array}$ & $\begin{array}{l}0.9 \\
0.1 \\
0.9\end{array}$ \\
\hline $\begin{array}{l}\text { Kebiasaan sehari- } \\
\text { hari }\end{array}$ & $\begin{array}{l}\text { Malas } \\
\text { Tidak }\end{array}$ & $\begin{array}{l}0.7 \\
0.1 \\
\end{array}$ \\
\hline
\end{tabular}

Sumber : European Journal of Scientific Research ISSN 1450-216X

Vol. 31 No. 4 (2009), pp. 642-656

Pada permasalahan ini arsitektur Jaringan Syaraf Tiruan yang digunakan adalah Jaringan Syaraf Tiruan dengan banyak lapisan (multi layer) dengan algoritma Backpropagation, yang terdiri dari:

a) Lapisan masukan (input) dengan $13 \operatorname{simpul}\left(x_{1}, x_{2}, x_{3}, x_{4}, x_{5}, x_{6}, x_{7}, x_{8}, x_{9}, x_{10}, x_{11}, x_{12}, x_{13}\right)$.

b) Lapisan tersembunyi (Hidden) dengan jumlah simpul ditentukan oleh pengguna $\left(Z_{1}, Z_{2}\right)$.

c) Lapisan keluaran (Output) dengan 1 simpul( $(Y)$.

Jaringan syaraf yang akan dibangun adalah algoritma propagasi balik (Backpropagation) dengan fungsi aktivasi Sigmoid. Fungsi aktivasi dalam jaringan syaraf tiruan dipakai untuk menentukan keluaran suatu Neuron.

\subsection{Hasil Pengujian Sistem}

Data diuji kedalam pola jaringan 13-2-1, 13-3-1, 13-4-1, 13-5-1, dan 13-6-1 dimana 13 unit input masukkan, unit hidden layer yang ditentukan secara acak 2 sampai 6 dan 1 unit output dengan fungsi aktivasi sigmoid. Berikut ini merupakan Plot Target vs Output pada tipe 13-6-1 dimana terlihat bahwa data memiliki error yang relatif kecil antara 0,0009 pada data ke-8 sampai 0,0727 pada data terakhir yaitu data ke- 
20, diperoleh persamaan regresi pada plot: $\mathrm{Y}=0,91 \mathrm{~T}+0,079$ dengan nilai koefisien korelasi $(\mathrm{r})$ sebesar 0,91205 , hasil ini merupakan hasil tebaik dari ke lima arsitektur yang diuji bahkan kecepatan perhitungan pun lebih cepat dengan 55 iterasi.

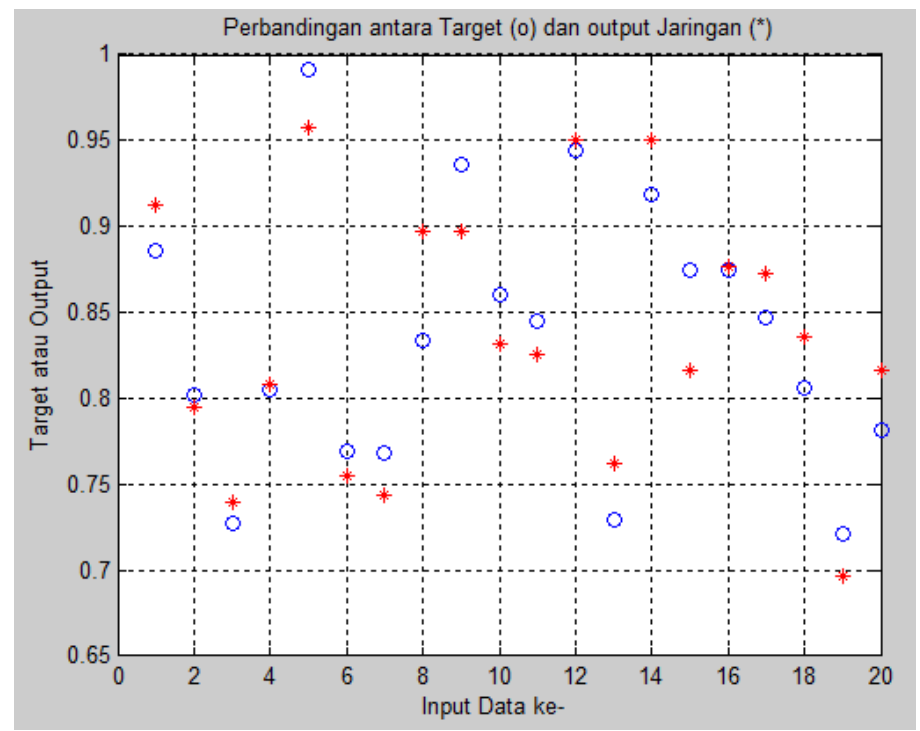

Gambar. 2. Plot Target vs Output pada tipe 13-6-1

Berikut ini adalah salah satu hasil plot jaringan dengan tipe 13-6-1 yang merupakan tipe arsitektur terbaik dalam mendeteksi pengidap penyakit jantung (Gambar 2).

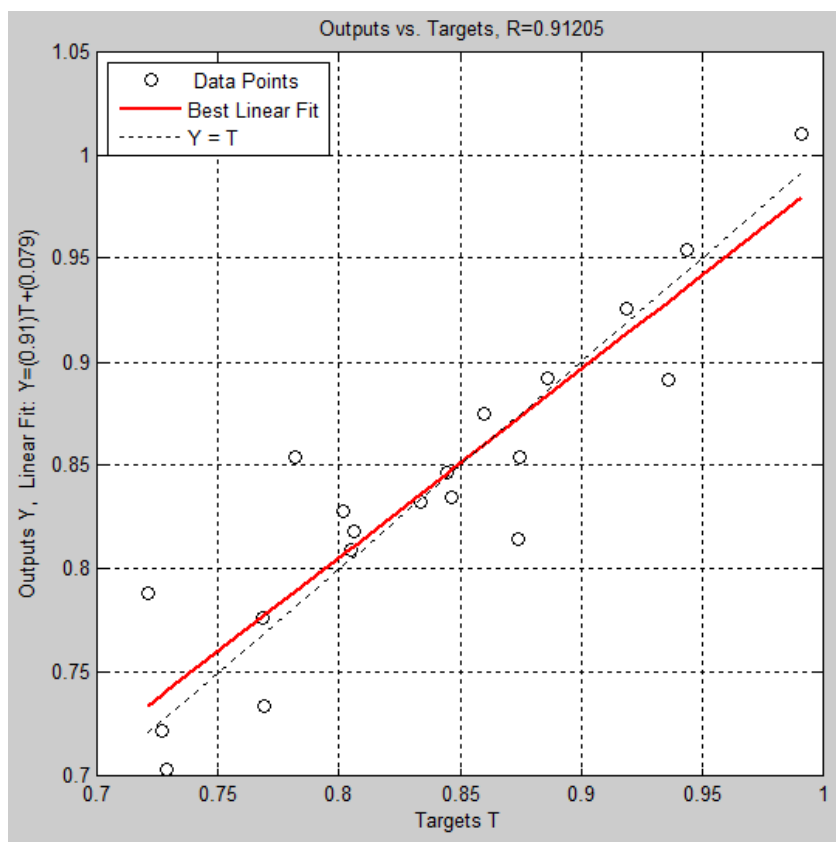

Gambar 2. Plot regresi hasil pengujian jaringan 13-6-1

Pengujian juga dilakukan terhadap 4 tipe yang lainnya yang menghasilkan keluaran tidak lebih baik dari tipe 13-6-1. Hasil lengkap pengujian 5 tipe arsitektur diperoleh rata-rata error minimum ada pada tipe 13-6-1, hasil lengkapnya pada Tabel 2 berikut. 
Tabel 2. Pengujian Sistem

\begin{tabular}{|c|c|c|c|c|c|}
\hline \multirow{2}{*}{ Data ke } & \multicolumn{5}{|c|}{ Tipe arsitektur } \\
\cline { 2 - 6 } & $\mathbf{1 3 - 2 - 1}$ & $\mathbf{1 3 - 3 - 1}$ & $\mathbf{1 3 - 4 - 1}$ & $\mathbf{1 3 - 5 - 1}$ & $\mathbf{1 3 - 6 - 1}$ \\
\hline 1 & 0.0017 & 0.0352 & 0.0090 & 0.0318 & 0.0060 \\
\hline 2 & 0.0847 & 0.0124 & 0.0333 & 0.0598 & 0.0264 \\
\hline 3 & 0.0000 & 0.0771 & 0.0361 & 0.0020 & 0.0053 \\
\hline 4 & 0.0055 & 0.0003 & 0.0021 & 0.0054 & 0.0038 \\
\hline 5 & 0.1049 & 0.0075 & 0.0162 & 0.0047 & 0.0187 \\
\hline 6 & 0.0002 & 0.0337 & 0.0042 & 0.0018 & 0.0350 \\
\hline 7 & 0.0019 & 0.0346 & 0.0038 & 0.0246 & 0.0076 \\
\hline 8 & 0.0029 & 0.0138 & 0.0032 & 0.0353 & 0.0009 \\
\hline 9 & 0.0527 & 0.0196 & 0.0433 & 0.0426 & 0.0445 \\
\hline 10 & 0.0265 & 0.0121 & 0.0109 & 0.0101 & 0.0153 \\
\hline 11 & 0.0417 & 0.0355 & 0.0021 & 0.0048 & 0.0020 \\
\hline 12 & 0.0649 & 0.1404 & 0.0037 & 0.0187 & 0.0103 \\
\hline 13 & 0.0036 & 0.0766 & 0.0094 & 0.0004 & 0.0256 \\
\hline 14 & 0.0325 & 0.0196 & 0.0044 & 0.0447 & 0.0072 \\
\hline 15 & 0.0106 & 0.0624 & 0.0885 & 0.0451 & 0.0203 \\
\hline 16 & 0.0176 & 0.0710 & 0.0087 & 0.0226 & 0.0593 \\
\hline 17 & 0.0058 & 0.0350 & 0.0004 & 0.0400 & 0.0120 \\
\hline 18 & 0.0004 & 0.0029 & 0.0225 & 0.0346 & 0.0121 \\
\hline 19 & 0.0034 & 0.0810 & 0.0812 & 0.0219 & 0.0668 \\
\hline 20 & 0.1036 & 0.0306 & 0.0045 & 0.0479 & 0.0727 \\
\hline
\end{tabular}

Dari kelima tipe arsitektur yang digunakan penulis dalam proses pengujian sistem Jaringan Syaraf Tiruan dengan algoritma Backpropagation dengan menggunakan matlab dengan sampel data sebanyak 20 orang data rekam medis, maka penulis menyimpulkan lebih baik menggunakan model 13-6-1. Dari hasil yang diperoleh model ini lebih selektif dalam mengolah data serta epoch (pengulangan) lebih sedikit digunakan untuk memperoleh error minimum.

Tabel. 3. Tabel Perbandingan Pengujian Jaringan

\begin{tabular}{|c|c|c|c|c|}
\hline Tipe arsitektur & b & r & m & Iterasi \\
\hline $13-2-1$ & 0.3036 & 0.7986 & 0.6369 & 316 \\
\hline $13-3-1$ & 0.3972 & 0.7066 & 0.5244 & 187 \\
\hline $13-4-1$ & 0.2031 & 0.9081 & 0.7586 & 128 \\
\hline $13-5-1$ & 0.1392 & 0.9103 & 0.8334 & 88 \\
\hline $13-6-1$ & 0.9077 & 0.9120 & 0.9077 & 55 \\
\hline
\end{tabular}

Ket: persamaan regresi: $Y=b T+m$ dimana $\mathrm{T}$ adalah target, $\mathrm{b}$ titik perpotongan dengan sumbu $\mathrm{y}, \mathrm{r}$ merupakan koefisien korelasi sedangkan $m$ adalah gradien garis hasil regresi linier

\section{Kesimpulan}

Diperoleh konfigurasi jaringan yang terbaik adalah tipe dengan 13 input dan 6 hidden layer dengan 1 output (13-6-1) dengan bobot terbaik yang sudah diperoleh dengan kemampuan jaringan mendeteksi seseorang terkena penyakit jantung koroner dengan skala error 0,0009 sampai 0,0727 yang dipandang sangat kecil error yang diperoleh dengan persamaan regresi yang terbentuk adalah $y=0,91 T+0,079$ dengan koefisien korelasi sebesar 0,91205. Sedangkan tingkat ketepatan tiap tipe arsitektur jaringan tergambar pada tabel 2. Berdasarkan hal tersebut Maka dapat diambil kesimpulan bahwa penggunaan JST tipe 13-6-1 dalam memprediksi penyakit jantung koroner terbukti memiliki nilai akurasi cukup tinggi dengan rentang error minimum sehingga dapat digunakan dalam prediksi PJK. 


\section{Daftar Pustaka}

[1] Effendy N., Subagja, Faisal A., Prediksi penyakit jantung koroner (PJK) berdasarkan faktor risiko menggunakan jaringan syaraf tiruan backpropagation, Seminar Nasional Aplikasi Teknologi Informasi 2008 (SNATI 2008), Yogyakarta, 21 Juni 2008.

[2] Fauset, L., Fundamentals of Neural Networks, New Jersey: Prentice Hall, 1994.

[3] Kemenkes RI. 2014. Info Datin: Situasi Kesehatan Jantung.

[4] Kusumadewi, S., 2004, "Membangun jaringan Syaraf Tiruan Menggunakan Matlab \& Excel Link". Yogyakarta: Graha Ilmu.

[5] Larandipa L. A, Pontia F.T, Triyanto D., 2013, Aplikasi Jaringan Syaraf Tiruan Untuk Diagnosa Penyakit Jantung Koroner (Pjk) Dengan Metode Backpropagation, Jurnal Coding Sistem Komputer Universitas Tanjungpura Volume 01 No. 1 (2013), hal 11 - 19 ISSN : 2338-493x

[6] Lestari M., 2014, Penerapan algoritma klasifikasi nearest neighbor (k-nn) untuk mendeteksi penyakit jantung, jurnal Faktor Exacta 7(4): 366-371, 2014

[7] Wahyuni E. G., Pridjodiprodjo, W., 2013, Prototype Sistem Pakar untuk Mendeteksi Tingkat Resiko Penyakit Jantung Koroner dengan metode Dempster-Shafer (Studi Kasus: RS. PKU Muhammadiyah Yogyakarta), IJCCS, Vol.7, No.2, July 2013, pp. 133 144, 